OPEN ACCESS

Edited by:

Maria Angela Sortino, University of Catania, Italy

Reviewed by:

Elena Marcello,

University of Milan, Italy Gaurav Bedse

Vanderbilt University, USA

${ }^{*}$ Correspondence:

Qihai Gong

gqh@zmc.edu.cn

Specialty section:

This article was submitted to Experimental Pharmacology and Drug

Discovery,

a section of the journal

Frontiers in Pharmacology

Received: 17 October 2016 Accepted: 21 February 2017

Published: 08 March 2017

Citation:

Yan L, Deng Y, Gao J, Liu Y, Li F, Shi J and Gong Q (2017) Icariside II

Effectively Reduces Spatial Learning and Memory Impairments in Alzheimer's Disease Model Mice Targeting Beta-Amyloid Production. Front. Pharmacol. 8:106 doi: 10.3389/fphar.2017.00106

\section{Icariside II Effectively Reduces Spatial Learning and Memory Impairments in Alzheimer's Disease Model Mice Targeting Beta-Amyloid Production}

\author{
Lingli Yan'1, Yuanyuan Deng', Jianmei Gao², Yuangui Liu' ${ }^{1}$, Fei Li', Jingshan Shi' and \\ Qihai Gong ${ }^{\text {* }}$ \\ ${ }^{1}$ Department of Pharmacology and Key Laboratory of Basic Pharmacology of Ministry of Education, Zunyi Medical \\ University, Zunyi, China, ${ }^{2}$ Department of Pharmacy, Zunyi Medical University, Zunyi, China
}

Icariside II (ICS II) is a broad-spectrum anti-cancer natural compound extracted from Herba Epimedii Maxim. Recently, the role of ICS II has been investigated in central nervous system, especially have a neuroprotective effect in Alzheimer's disease (AD). In this study, we attempted to investigate the effects of ICS II, on cognitive deficits and beta-amyloid (A $\beta$ ) production in APPswe/PS1dE9 (APP/PS1) double transgenic mice. It was found that chronic ICS II administrated not only effectively ameliorated cognitive function deficits, but also inhibited neuronal degeneration and reduced the formation of plaque burden. ICS II significantly suppressed $A \beta$ production via promoting non-amyloidogenic APP cleavage process by up-regulating a disintegrin and metalloproteinase domain 10 (ADAM10) expression, inhibited amyloidogenic APP processing pathway by down-regulating amyloid precursor protein (APP) and $\beta$-site amyloid precursor protein cleavage enzyme 1 (BACE1) expression in APP/PS1 transgenic mice. Meanwhile, ICS II attenuated peroxisome proliferator-activated receptor- $\gamma$ (PPAR $\gamma$ ) degradation as well as inhibition of eukaryotic initiation factor $\alpha$ phosphorylation (p-elF2 $\alpha$ ) and PKR endoplasmic reticulum regulating kinase phosphorylation (p-PERK). Moreover, phosphodiesterase type 5 inhibitors (PDE5-Is) have recently emerged as a possible therapeutic target for cognitive enhancement via inhibiting $A \beta$ levels, and we also found that ICS II markedly decreased phosphodiesterase-5A (PDE5A) expression. In conclusion, the present study demonstrates that ICS II could attenuate spatial learning and memory impairments in APP/PS1 transgenic mice. This protection appears to be due to the increased ADAM10 expression and decreased expression of both APP and BACE1, resulting in inhibition of $A \beta$ production in the hippocampus and cortex. Inhibition of PPAR $\gamma$ degradation and PERK/elF2 $\alpha$ phosphorylation are involved in the course, therefore suggesting that ICS II might be a promising potential compound for the treatment of AD.

Keywords: icariside II, Alzheimer's disease, beta-amyloid, a disintegrin and metalloproteinase domain 10, betasite APP cleavage enzyme 1, peroxisome proliferator-activated receptor- $\gamma$ 


\section{INTRODUCTION}

Alzheimer's disease is the most common age-related neurodegenerative disorder. Its primary clinical symptom is progressive cognitive function deterioration, such as impaired communication, confusion, and poor judgment (Alzheimer's Association, 2015). It is estimated that as many as 46.8 million people worldwide are suffering from dementia in 2015 and the number of $\mathrm{AD}$ patients rises by more than 11 million people per year, which leads to a tremendous burden on the society and the family (Carrillo et al., 2013; Alzheimer's Association, 2015). Clinically, the hallmarks of AD include the deposition of senile plaques, which are comprised of $A \beta$ peptides neurofibrillary tangles (NFTs), and the death of neurons accompanied by synapses loss (Yang R.Y. et al., 2015). Although the pathogenesis of $\mathrm{AD}$ is complicated and the mechanisms governing this disease remains elusive, extensive studies suggest that $A \beta$ cascade hypothesis remains dominating the $\mathrm{AD}$ research, which centers on $A \beta$ as the most critical initiator in the pathogenesis of $A D$ (Sun et al., 2015; Sengupta et al., 2016). A $\beta$ results from the sequential proteolytic processing of APP by BACE1 (as the rate-limiting secretase) and $\gamma$-secretase, the cleavage step is contributes much to AD pathology (Zhang and Song, 2013). However, in the non-amyloidogenic cleavage process, APP is cleaved by $\alpha$-secretase (a large metallopeptidase family, known as ADAM) to produce non-toxic fragments, which is deemed to antagonize A $\beta$ generation (Vassar, 2013; Sun et al., 2015). Excessive accumulation and aggregation of $A \beta$ result in neurotoxicity in the nervous system, inducing neuronal degeneration and eventually the death of neurons (Zhu et al., 2013), which further causes memory deficits (Sun et al., 2015). Currently clinical available pharmacotherapies of $\mathrm{AD}$ include acetylcholinesterase inhibitors (such as donepezil, tacrine, rivastigmine, and galantamine) and $\mathrm{N}$-methyl-D-aspartate receptor antagonists (memantine) (Fan and Chiu, 2014). Given that the etiology of $\mathrm{AD}$ is multiple, these agents only ameliorate certain symptoms but do not change or delay the progress of $\mathrm{AD}$ which substantially limits their clinical utilities (Anand et al., 2013). Thus, new therapies for $\mathrm{AD}$ are in dire need.

Among numerous therapeutic strategies of AD, BACE1 has always attracted much attention to investigate it's biological function on $A P P-A \beta$ process. Increasing evidence indicated that BACE1 overexpression and $A \beta$ accumulation were observed in brains of $\mathrm{AD}$ mouse models and patients. However, $\mathrm{A} \beta$ and $\beta$-secretase-cleaved APP fragments were decreased in BACE1knockdown model mice (Sankaranarayanan et al., 2008). Thus, the relationship between $\mathrm{BACE} 1$ and $\mathrm{A} \beta$ production has explicitly point out that screening out compound for decreasing BACE1 level for against $\mathrm{AD}$. But to date, majority of compounds that

Abbreviations: $\mathrm{A} \beta$, beta-amyloid; AD, Alzheimer's disease; ADAM10, a disintegrin and metalloproteinase domain 10; APP, amyloid precursor protein; APP/PS1, APPswe/PS1dE9; BACE1, $\beta$-site APP cleavage enzyme 1; eIF2 $\alpha$, eukaryotic initiation factor $\alpha$; ICS II, icariside II; MWM, Morris water maze; NFTs, neurofibrillary tangles; NS, normal saline; PBS, phosphate buffer saline; PDE5-Is, phosphodiesterase type 5 inhibitors; PDE5A, phosphodiesterase type 5A; PERK, PKR endoplasmic reticulum regulating kinase; $\operatorname{PPAR} \gamma$, peroxisome proliferatoractivated receptor- $\gamma$; $\operatorname{sAPP} \alpha$, soluble APP- $\alpha$; $\operatorname{sAPP} \beta$, soluble APP- $\beta$; WT, wild type. inhibiting BACE1 still exist many side effects in clinical trials (including peptides and synthetic). Several natural compounds isolated from Chinese medical herbs, such as ginsenoside, because of its pharmacological safety and therapeutic potential, which are widely applied in prophylaxis and treatment of various illness (Yang X.-D. et al., 2015; Cao et al., 2016; Xie et al., 2016).

Herba Epimedium is a popular Chinese medicinal plant, traditionally used as cardiovascular diseases and cancer therapy (Sze et al., 2010). One of its bioactive flavonoid compounds, ICS II, shows good CNS penetration and robust biological activities. ICS II protect against cerebral ischemia reperfusion injury in rats via an integrated mechanism of nuclear factor- $\kappa \mathrm{B}$ inhibition and peroxisome proliferator activated receptor up-regulation (Deng et al., 2016). Similarly, ICS II alleviates hippocampal injury in a gerbil model of ischemia-reperfusion (Yan et al., 2014). In addition, our previous research has shown that ICS II attenuates streptozotocininduced cognitive deficits and neuronal degeneration, the level of $\mathrm{A} \beta$ contents are also decreased in rats, the underlying mechanisms of which may be associated with the inhibition of BACE1 level (Zhang and Song, 2013; Yin et al., 2016). However, it is unclear whether ICS II could ameliorate cognitive function impairments via inhibiting multiple pathogenic pathways of $\mathrm{A} \beta$ production in APP/PS1 transgenic mice.

In this study, APP/PS1 transgenic mice were utilized to examine whether chronic treatment of ICS II could improve spatial learning and ameliorate memory impairments. We also examined the underlying biochemical mechanisms related to the behavioral changes. Here we show that ICS II effectively ameliorated cognitive functions deficits via inhibiting neuronal loss and the formation of senile plaques, at least partly, by decreasing $A \beta$ production.

\section{MATERIALS AND METHODS}

\section{Reagents}

Icariside II $\geq 98 \%$ by (HPLC), which was provided from Nanjing Zelang Medical Technology Corporation Ltd (China). All related experiment reagents were reagent grade and commercially available.

\section{Animals}

All male APPswe/PS1dE9 transgenic model mice (APP/PS1) and their littermates WT mice (weighing 30-35 g) were obtained from the Model Animal Research Centre of Nanjing University. Mice were allowed to acclimatize under SPF-class animal housing of laboratory (certificate no. SYXK 2011-004) at Zunyi Medical University, with $12 \mathrm{~h}$ light/dark cycle, temperature $\left(22 \pm 1^{\circ} \mathrm{C}\right)$, relative humidity $(60-70 \%)$, food and drinking water were available ad libitum. Animal experiments were strictly implemented according to the State Committee of Science and Technology of the People's Republic of China Order No. 2 on November 14, 1988 (revised 2011) and the protocols in this study were allowed by the Animal Experimentation Ethics Committee of the Zunyi Medical University. 


\section{Animal Treatments}

Nine-month-old male APP/PS1 transgenic mice were randomized divided into three groups: ICS II treated groups $(10 \mathrm{mg} / \mathrm{kg}, n=12 ; 30 \mathrm{mg} / \mathrm{kg}, n=13)$ and APP/PS1 control group $(n=12)$. Age-matched male WT mice were randomized assigned to three groups: ICS II treated groups $(10$ and $30 \mathrm{mg} / \mathrm{kg}$, $n=10)$ and WT control group $(n=10)$. APP/PS1 and WT treated groups were orally administered with ICS II dissolved in NS at a dose of $10,30 \mathrm{mg} / \mathrm{kg}$ body weight once daily, and control groups received volume-matched NS for 3 months.

\section{Morris Water Maze (MWM) Test}

After 3 months of treatment, MWM task was applied to evaluate cognitive abilities of the mice (under the condition of experimenters blinded to the treatments). In brief, the apparatus consisted of a circular white plastic water tank (the diameter was $120 \mathrm{~cm}$ and height was $50 \mathrm{~cm})$ and filled with water $\left(24 \pm 1^{\circ} \mathrm{C}\right)$ to a depth of $30 \mathrm{~cm}$, the area of tank was divided into four quadrants of equal size, a removable circular platform of perspex ( $9.5 \mathrm{~cm}$ diameter, $29 \mathrm{~cm}$ height) was hidden in the midpoint of the third quadrant and submerged $1 \mathrm{~cm}$ beneath the surface of water for all trials and sessions. Spatial acquisition ability was measured during four consecutive days, during which the mouse was released into the water that one of the four quadrants and allowed $60 \mathrm{~s}$ to reach the hidden platform and keep on it for $20 \mathrm{~s}$, and the escape latency (swim toward the hidden platform and keep on it for more than $3 \mathrm{~s}$ ) were recorded. If mice failed to found the hidden platform within preset time (the escape latency was recorded as $60 \mathrm{~s}$ ), and it would be softly guided to the hidden platform where it remained on top of the platform for $20 \mathrm{~s}$. Per mouse was experimented to four trials per day and the inter-trial interval was $20 \mathrm{~min}$. A probe trial was performed in the fifth day to measure the final spatial memory consolidation (hidden platform was withdrawn). The percentage of time of each mouse was recorded during a $60 \mathrm{~s}$ trial. These activities in all trials were automatically measured and analyzed by using the behavior analyzing system (TopScan Version 3.00).

\section{Tissue Preparation}

All animals were deeply anesthetized with sodium pentobarbital (50 $\mathrm{mg} / \mathrm{kg}$ intraperitoneally) after MWM test, and mice ( $n=4-5$ per group) were perfused transcardially with ice-cold $0.01 \mathrm{M}$ phosphate-buffered saline ( $\mathrm{PBS}, \mathrm{pH}=7.4$ ), followed by the precooled $4 \%$ buffered paraformaldehyde $(\mathrm{pH}=7.4)$, then the brain was instantly removed and stored in fresh fixative at $4^{\circ} \mathrm{C}$ overnight. The right hemispheres of brains were dehydrated through the gradient of 20 and 30\% sucrose solutions until sank at $4^{\circ} \mathrm{C}$. The respective left hemispheres were embedded by paraffin. For other animals ( $n=6-8$ per group), the hippocampus and cortex were immediately isolated and stored at $-80^{\circ} \mathrm{C}$ with Eppendorf micro test tubes.

\section{Thioflavine S and NissI Staining}

The right hemispheres of brains were serially cut using a cryostat (Leica CM 1850 UV; Leica, Nussloch, Germany) at $30 \mu \mathrm{m}$ thickness sections in the coronal plane. The brain slices were collected sequentially in 24-well plates, which filling with antifreezing solution and stored at $-20^{\circ} \mathrm{C}$. To observe the formation of senile plaques in hippocampus of mice, the brain slices were placed in a $1 \%$ thioflavine S (Lot\# SLBG4212V, Sigma, USA) for $10 \mathrm{~min}$, and then eluted with $70 \%$ alcohol, and finally washed with PBS three times and mounted with glycerin jelly, with all of the steps carefully kept away from light. The green fluorescence-tagged senile plaques were examined under a fluorescence microscope (BX53+DP80, Olympus, Japan). The numbers of senile plaques in the hippocampus were counted by Image-Pro Plus (Media Cybernetics, Bethesda, MD, USA). Meanwhile, the left hemispheres of brains fixed with fresh $4 \%$ paraformaldehyde solution for 1 week at $4^{\circ} \mathrm{C}$, Finally, the samples were embedded in paraffin. Three-micrometerthick brain tissue coronal sections of mice were stained with toluidine blue (Solarbio, China). The Nissl bodies were stained blue-purple in the CA3 and DG regions of hippocampus. The morphological changes (normal neurons having granular cytoplasm and euchromatic nucleus with large nucleoli) were observed under a light microscope (KS300, Zeiss-Kontron, Germany). Viable neurons in the CA3 and DG region of hippocampus from each group were counted as previously described (Liu et al., 2015).

\section{Western Blot Analysis}

Hippocampus and cortex tissues ( $n=3-4$ per group) were homogenized at $4^{\circ} \mathrm{C}$ in the radio-immunoprecipitation (RAPI) assay lysis buffer containing complete protease inhibitor mixture by using a plastic homogenizer and then sonicated for $30 \mathrm{~min}$ on an ice plate. The homogenized tissue were centrifuged for $15 \min \left(12000 \times g, 4^{\circ} \mathrm{C}\right)$, and supernatant was extracted and subpackaged, finally stored at $-80^{\circ} \mathrm{C}$. The concentrations of total protein were tested by BCA protein assay kit (Beyotime, China), and equal amounts of protein (approximately 25 or $30 \mu \mathrm{g}$ ) were heat-denatured at $100^{\circ} \mathrm{C}$ for $5 \mathrm{~min}$, electrophoretically separated using $6-12 \%$ SDS-PAGE gels, electrophoretic transferred onto the PVDF membranes $(0.45 \mu \mathrm{m})$. Membranes were then blocked with $2 \%$ BSA or $5 \%$ defatted in $1 \times$ TBST for $1-$ $3 \mathrm{~h}$ and next probed with corresponding primary antibodies against APP (1:1,000, AB60097b, BBB Life sciences, USA), $\mathrm{A} \beta_{1-40}$ (1:1,000, MAB2675, Abnova, USA), $\mathrm{A} \beta_{1-42}(1: 1,000$, \#14974, CST, USA), PDE5A1 (1:1,000, ab14672, Abcam, USA), sAPP $\alpha$ (2B3) (1:500, Immuno-Biological Laboratories, USA), ADAM10 (1:500, ab124695, Abcam, USA), sAPP $\beta$ (6A1) antibody (1:500, Immuno-Biological Laboratories, USA), BACE1 (1:1,000, ab108394, Abcam, USA), PPAR $\gamma$ (1:500, ab19481, Abcam, USA), p-PERK (Thr981) (1:200, sc-32577, Santa Cruz Biotechnology, USA), total PERK (1:200, sc-13073, Santa Cruz Biotechnology, USA), p-eIF2 $\alpha$ (Ser51) (1:200, ab32157, Abcam, USA), total eIF2 $\alpha$ (1:500, ab5369, Abcam, USA), and $\beta$-actin (1:2,000, AA128, Beyotime, China) overnight at $4^{\circ} \mathrm{C}$. After incubation with appropriate HRP-conjugated secondary antibodies for $1-2 \mathrm{~h}$ at room temperature, the immunoreactive protein was exhibited with ECL detection reagent (Beyotime, China) and the densitometry of band was analyzed using Quantity One-4.6.7. (Bio-Rad, USA). 


\section{Statistics}

The data were presented as mean \pm SEM. All statistical analyses were performed using SPSS software, version 17.0 (SPSS, Chicago, IL, USA). MWM task data were analyzed using repeated measures analysis of variance (ANOVA). Firstly, Mauchly's test of sphericity should be used to judge whether there were relations among the repeatedly measured data. If any $(P<0.05)$, and the Greenhouse-Geisser corrected results should be taken. With multivariate ANOVA, date in different treated group of each measurement time could be compared pairwise.

For the data that did not involve repeated measures, they were analyzed using one-way ANOVA. If the ANOVA test results were significant, the individual differences among different groups or conditions were determined by post hoc least significant difference (LSD). A probability value of $<0.05$ was statistically considered significant differences.

\section{RESULTS}

\section{Effects of ICS II on Spatial Learning and Memory in APP/PS1 Transgenic Mice}

To investigate the effects of ICS II on cognitive deficits in APP/PS1 transgenic mice, the spatial learning and memory of all mice were evaluated through the MWM. The $P$-value of Mauchly's Test of Sphericity in escape latency was less than 0.05 $(P=0.017)$, which did not accept the sphericity assumption. Then the Greenhouse-Geisser correction was used, and the main effect of "latency between days" and "latency between groups" was significant difference $\left[F_{(2.619,157.127)}=55.309, p<0.001\right]$ and $\left[F_{(5,60)}=2.912, p=0.02\right]$, respectively. The interaction of "days $\times$ groups" was no significant $\left[F_{(13.094,157.127)}=1.520\right.$, $p=0.115]$. During the consecutive 5 days of training, acquisition ability of spatial learning and memory were measured (Figure 1). In the navigation test, as illustrated in Figure 1B, the escape latency of all mice was gradually shortened and their ability to locate the platform was improved with the training. On days 2-4 (Figure 1B), APP/PS1 transgenic mice showed increased mean escape latencies $(p<0.05)$. With the chronic treatment with ICS II at the dose of $30 \mathrm{mg} / \mathrm{kg}$, no obvious differences in mean escape latencies were observed on the first and second days compared with APP/PS1 control group, while notable differences were detected on the third and fourth days $(p<0.05$, $p<0.05$, respectively). Interestingly, on days $2-3$, the mean escape latencies were reduced after treatment with ICS II at the dose of $10 \mathrm{mg} / \mathrm{kg}$ for 3 months ( $p<0.05, p<0.01$, respectively). But there was no noticeable change on day $4(p>0.05)$.

The percentage of time that animals spent in the target quadrant during the search for the platform in probe trial is shown in Figure 1C. There was a very low percentage on time spent in target quadrant in APP/PS1 control group $(p<0.01)$ $\left[F_{(5,60)}=6.860, p<0.001\right]$, indicative of cognitive function deficits. Nevertheless, ICS II (10 mg/kg) treated group spent more time in the target quadrant $(p<0.01)$. Similar effect was observed at a larger dose of ICS II $(30 \mathrm{mg} / \mathrm{kg})(p<0.01)$. In addition, the swimming speed did not show significant differences among the groups, suggesting that ICS II treatment did not affect the motor ability in mice. Together, these results indicated that chronic treatment of ICS II could ameliorate the spatial learning and memory impairments in APP/PS1 transgenic mice.

\section{The Effects of ICS II on Neuronal Cells in the Hippocampus of APP/PS1 Transgenic Mice}

The viable neuron is believed to be an especially important role in the learning and memory functions. Therefore, the number of neuronal cells in the CA3 and DG regions of hippocampus were evaluated to investigate the effects of ICS II treatment on the neuronal morphology change by Nissl staining. As the shown in Figure 2A, normal morphological features of pyramidal cells is intact structure, including granular cytoplasm and whereas the apparent pathological changes with loosely arranged neurons and less neurons were found in APP/PS1 transgenic mice hippocampal CA3 and DG regions, viable neurons were counted using three equally spaced coronal sections passing through the hippocampus for each brain $\left[F_{(5,12)}=3.359, p=0.04\right.$; $\left.F_{(5,12)}=4.975, p=0.011\right](p<0.05 ; p<0.01)$ (Figures 2B,C). The mean numbers of neurons were clearly more with ICS II treatment than controls $(p<0.05$; $p<0.05)$. Overall, these data demonstrated that ICS II attenuated neuronal death in APP/PS1 transgenic mice.

\section{Effects of ICS II on Senile Plaque Formation in the Hippocampus of APP/PS1 Transgenic Mice}

In the brain of $\mathrm{AD}$ patients, the most remarkable neuropathological feature is $A \beta$ overproduction, which ultimately causes the formation of senile plaque. In the present study, we evaluated the effects of ICS II on the formation of senile plaque in coronal sections of hippocampus from different groups (Figure 2D). Senile plaque formation was not found in WT mice at the age of 12 months, in contrast, thioflavine $S$ staining revealed the presence of extensive senile plaques in the hippocampus of age-matched APP/PS1 transgenic mice. Importantly, quantification analysis exhibited that the amyloid burden (\% of total areas) was remarkably reversed by ICS II $\left[F_{(2,6)}=9.116, p=0.015\right](p<0.01)$ (Figure $2 \mathrm{E}$ ), whereas was not found difference in low dose of ICS II $10 \mathrm{mg} / \mathrm{kg}$. Simultaneously, the number of amyloid plaque was significantly decreased in APP/PS1 transgenic mice treated with ICS II $(10 \mathrm{mg} / \mathrm{kg}$ ) when compared with APP/PS1 transgenic mice $\left[F_{(2,6)}=3.618, p=0.093\right](p<0.05)$ (Figure 2F). Taken together, these results suggested an inhibitory effect of ICS II on amyloid plaque formation.

\section{Effects of ICS II on the Levels of $A \beta_{1-42}$ and $A \beta_{1-40}$ in the Hippocampus and Cortex of APP/PS1 Transgenic Mice}

Since accumulating evidence indicates that $\mathrm{AD}$ mice exhibits accelerated $A \beta$ production in the brain with increasing age. Thus, the levels of $A \beta$ contents in the hippocampus and cortex of mice were subsequently examined using Western 

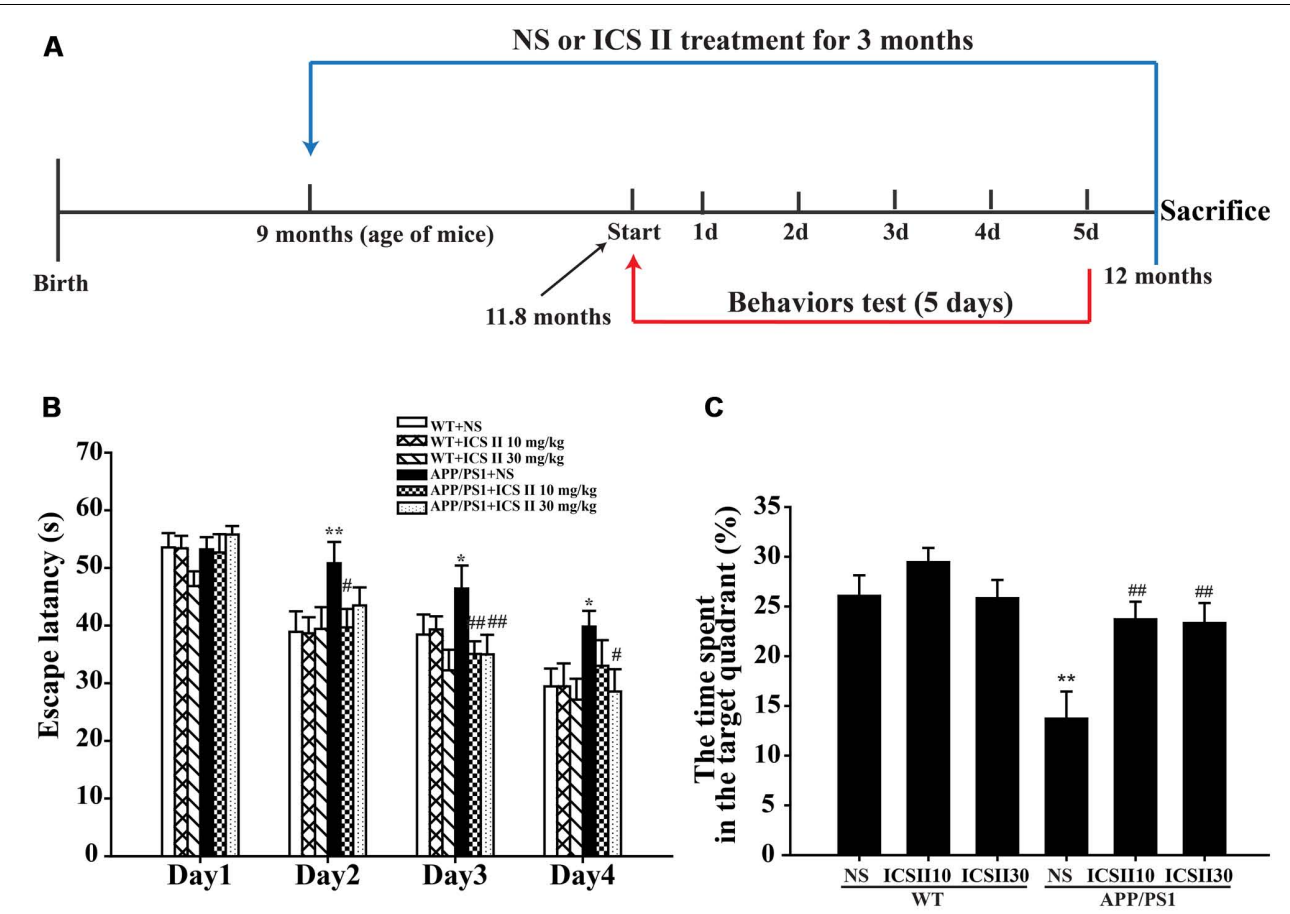

FIGURE 1 | Effects of ICS II on spatial learning and memory functions in APP/PS1 transgenic mice. (A) The flow chart of animal experiments. (B) The escape latency of mice to reach the hidden platform from day 1 to day 4 . (C) The percent of time that mice swimming in the target quadrant. Values were expressed as mean \pm SEM $(\mathrm{WT}+\mathrm{NS}, n=9$; WT $+\mathrm{ICS}\|10 \mathrm{mg} / \mathrm{kg}, n=10 ; \mathrm{WT}+\mathrm{ICS}\| 30 \mathrm{mg} / \mathrm{kg}, n=10 ;$ APP/PS1+NS, $n=12 ;$ APP/PS1 + ICS $\| 10 \mathrm{mg} / \mathrm{kg}, n=12 ;$ WT+ICS II $30 \mathrm{mg} / \mathrm{kg}, n=13),{ }^{*} p<0.05,{ }^{* *} p<0.01$ vs. WT+NS, ${ }^{\#} p<0.05,{ }^{\# \#} p<0.01$ vs. APP/PS1+NS. Abbreviation: SEM, standard error of the mean; NS, normal saline.

blot. As depicted in Figures 3A-D, the levels of $\mathrm{A} \beta_{1-42}$ $(p<0.001 ; p<0.01)$ [Hippocampus $\left(F_{(5,12)}=9.007, p<0.001\right)$; Cortex $\left.\left(F_{(5,12)}=5.667, p<0.01\right)\right]$ and $\mathrm{A} \beta_{1-40}(p<0.001$; $p<0.01)$ [Hippocampus $\left(F_{(5,12)}=29.012, p<0.001\right)$; Cortex $\left.\left(F_{(5,12)}=3.869, p=0.025\right)\right]$ were markedly enhanced in APP/PS1 transgenic mice. However, after treated with two doses of ICS II resulted in a dramatic reduction in both $A \beta_{1-42}$ and $\mathrm{A} \beta_{1-40}(p<0.01 ; p<0.05)(p<0.01 ; p<0.01)$. In addition, ICS II treatment in WT mice did not facilitate the $\mathrm{A} \beta$ levels. Together, these results indicated that long-term ICS II treatment significantly reduces $A \beta_{1-42}$ and $A \beta_{1-40}$ levels.

\section{Effects of ICS II on Process of A $\beta$ Production in the Hippocampus and Cortex of APP/PS1 Transgenic Mice}

Abnormally increased $A \beta$ production closely correlates with the secretases of APP cleavage process, therefore we next assessed the process of APP changes which could contributes to the decreased $\mathrm{A} \beta$ production. As showed in Figures $4 \mathrm{~A}-\mathbf{L}$, quantitative analysis results indicated significant differences in the protein level of APP in APP/PS1 model group compared with WT control group $(p<0.01 ; p<0.01)$ [Hippocampus $F_{(5,12)}=10.670$, $p<0.001$; Cortex $F_{(5,12)}=20.739, p<0.001$ ] (Figures 4B,J). Moreover, chronic treatment with ICS II significantly suppressed the APP level in a concentration dose-dependent manner $(p<0.01 ; p<0.05)$. Because two key enzymes, ADAM10 and BACE1, are involved in the initial cleavage of APP, we further analyzed the ADAM10, BACE1 protein expressions and the levels of major APP-cleaved product ( $\mathrm{APP} \alpha$ and $\mathrm{sAPP} \beta)$. Quantitative analysis showed that ICS II treatment markedly increased the level of $\operatorname{sAPP} \alpha$ [Hippocampus $F_{(2,6)}=7.515$, $p=0.023$ and Cortex $\left.F_{(2,6)}=18.272, p=0.003\right](p<0.01$; $p<0.01$ ) and decreased the level of sAPP $\beta$ [Hippocampus $F_{(2,6)}=7.662, p=0.022$ and Cortex $F_{(2,6)}=46.559$, $p<0.001](p<0.05 ; p<0.01)$ in APP/PS1 control group. However, the dose of $10 \mathrm{mg} / \mathrm{kg}$ ICS II did not change the levels of sAPP $\alpha$ in the hippocampus $(p=0.183)$ and cortex $(p=0.242)$.

Moreover, in the APP/PS1 transgenic mice, the ADAM10 level was dramatically reduced relative to WT control group [Hippocampus $F_{(5,12)}=5.177, p=0.009$ and Cortex $\left.F_{(5,12)}=8.221, p=0.001\right](p<0.01 ; p<0.01)$ (Figures 4D,I). In contrast, the protein levels of BACE1 were clearly enhanced $(p<0.01 ; p<0.01)$ [Hippocampus $F_{(5,12)}=4.427, p<0.05$ and Cortex $F_{(5,12)}=9.304, p<0.01$ ] (Figures 4F,L). Interestingly, ICS II $(30 \mathrm{mg} / \mathrm{kg})$ could also blunt the down-regulation of ADAM10 $(p<0.01 ; p<0.01)$. ICS II $(10,30 \mathrm{mg} / \mathrm{kg})$ significantly down-regulated the BACE1 protein levels $(p<0.05 ; p<0.01)$ and no differences were found among the WT animals. These results may suggest that ICS II inhibited A $\beta$ production via reducing the protein expression of APP and BACE1 and inducing ADAM10 protein expression in APP/PS1 transgenic mice. 

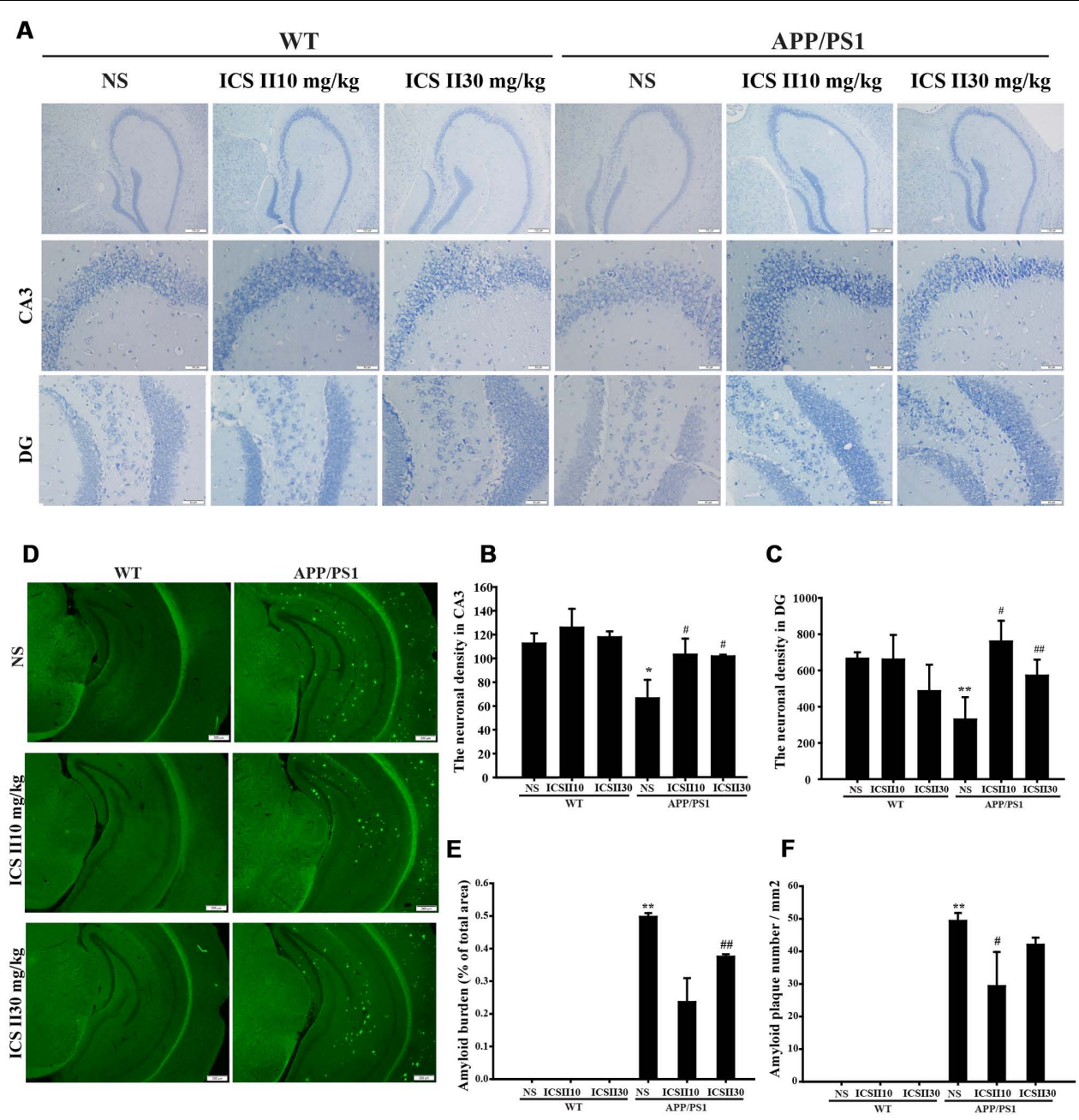

FIGURE 2 | Effects of ICS II on neuronal cells and senile plaque formation in the hippocampus of APP/PS1 transgenic mice. (A) Representative photomicrographs of Nissl staining results of each group (magnification $400 \times$, scale bar $=50 \mu \mathrm{m}$ ). (B,C) Statistics of viable neurons in the hippocampal CA3 and DG regions. (D) Images of thioflavine S-stained senile plaques results of each group (magnification $40 \times$, scale bar $=200 \mu \mathrm{m}$ ). (E,F) Statistics of thioflavine $\mathrm{S}$-stained amyloid burden and amyloid plaques number in the hippocampus. Values were expressed as mean $\pm \mathrm{SEM}\left(n=3\right.$ each), * $p<0.05,{ }^{* *} p<0.05$ vs. WT+NS, ${ }^{\#} p<0.05,{ }^{\#} p<0.01$ vs. APP/PS1+NS. SEM, standard error of the mean; NS, normal saline.

\section{The Inhibition of elF2 $\alpha$ and PERK}

\section{Phosphorylation Mediated Pathway and Suppression of PPAR $\gamma$ Degradation Were Involved in the ICS II-Reduced BACE1 Effect in APP/PS1 Transgenic Mice}

Phosphorylation eIF2 $\alpha /$ PERK and PPAR $\gamma$ are important signaling pathway could regulate BACE1 levels. Thus, we next examined whether ICS II could inhibited the level of p-eIF $2 \alpha$ or p-PERK in the brains of APP/PS1 transgenic mice (Figures 5A,B). The levels of p-eIF $2 \alpha[$ Hippocampus $F_{(5,12)}=5.632, p=0.007 ;$ Cortex $F_{(5,12)}=5.597$, $p=0.007](p<0.01 ; p<0.001)$ and p-PERK $(p<0.01$; $p<0.05)$ [Hippocampus $F_{(5,12)}=10.561, p<0.001$; Cortex $\left.F_{(5,12)}=2.743, p=0.071\right]$ in $\mathrm{APP} / \mathrm{PS} 1$ transgenic mice both were much higher than WT control group (Figures 5C,D), which is in agreement with previous studies and also consistent with the results of BACE1 level. Chronic ICS II $(30 \mathrm{mg} / \mathrm{kg})$ treatment significantly inhibited the levels of p-eIF $2 \alpha(p<0.01$; $p<0.05)$ and p-PERK $(p<0.01 ; p<0.05)$. The results further support the notion that ICS II has neuroprotective effect in APP/PS1 transgenic mice and that the mechanisms may involve the reduction of BACE1 via dephosphorylation of eIF2 $\alpha /$ PERK. Another transcription factor, PPAR $\gamma$, can regulate $\mathrm{BACE} 1$ activity and reduce $\mathrm{A} \beta$ production. Here, we also examined the PPAR $\gamma$ level in the hippocampus and cortex of APP/PS1 transgenic mice (Figures 5A,B). As compared to WT control group, APP/PS1 transgenic mice exhibited a lower level of PPAR $\gamma$ in different brain regions $(p<0.01$; $p<0.01)$ [Hippocampus $F_{(5,12)}=7.045, p=0.003$; Cortex $F_{(5,12)}=10.064, p=0.001$ ] (Figure 5E). It is therefore possible that at least part of the activation of PPAR $\gamma$ expression was 
A

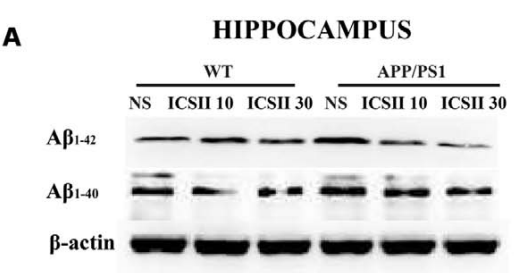

C

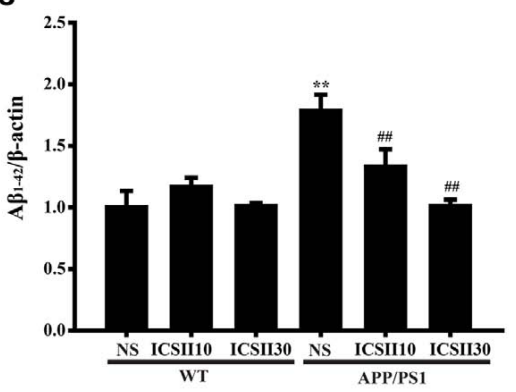

D

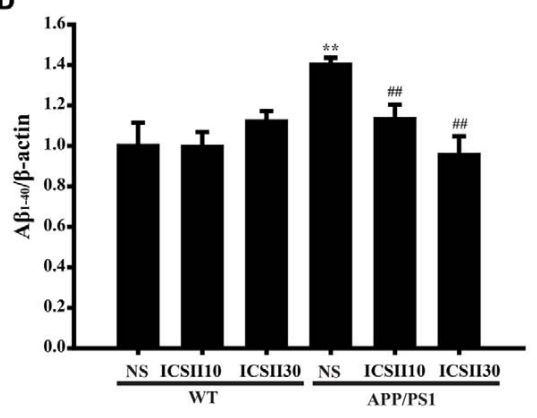

B
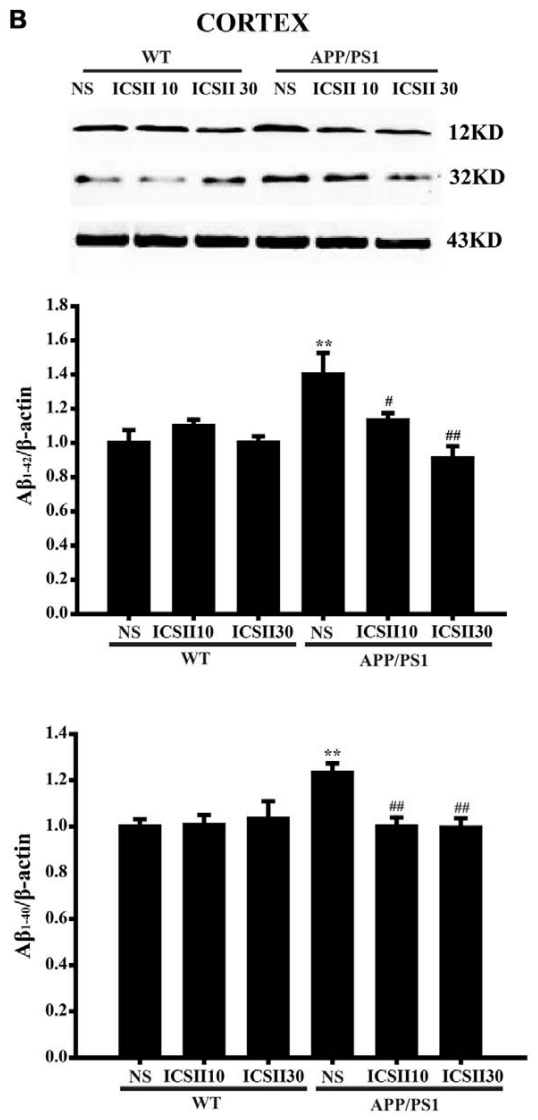

FIGURE 3 | Effect of ICS II on the levels of $A \beta_{1-42}$ and $A \beta_{1-40}$ in the hippocampus and cortex of APP/PS1 transgenic mice. (A,B) The antibody-reactive bands of $A \beta_{1-42}$ and $A \beta_{1-40}$ in the hippocampus and cortex of different groups. (C) Quantitative analysis of $A \beta_{1-42}$ levels. (D) Quantitative analysis of $A \beta_{1-40}$ levels. The relative optical density was normalized to $\beta$-actin. Data are presented as mean $\pm \operatorname{SEM}\left(n=3\right.$ each), ${ }^{* *} p<0.01$ vs. WT+NS, ${ }^{\#} p<0.05$, ${ }^{\# \#} p<0.01$ vs. APP/PS1+NS. SEM, standard error of the mean; NS, normal saline; A $\beta$, Amyloid- $\beta$.

related to the level of BACE1, which could contribute to suppression of $A \beta$ production.

\section{Effects of ICS II on Protein Levels of PDE5A in the Hippocampus and Cortex of APP/PS1 Transgenic Mice}

The PDE5A level was also measured in the hippocampus and cortex of APP/PS1 transgenic mice by using the PDE51 antibody $(p<0.01, p<0.05)$. Following ICS II treatment for 3 months, a markedly reduced PDE5A level was seen in the hippocampus and cortex with a dose-dependent manner [Hippocampus $F_{(5,12)}=4.261, p<0.05$ and Cortex $\left.F_{(5,12)}=4.806, p<0.05\right]$ $(p<0.05, p<0.05)$ (Figures 6A-C). This result clearly demonstrated that the overexpression level of PDE5A in hippocampus and cortex of APP/PS1 transgenic mice could be attenuated by ICS II.

\section{DISCUSSION}

This study demonstrated that ICS II protected against spatial learning and memory impairments, decreased senile plaque and
$\mathrm{A} \beta$ levels, and promoted viable neuron as well as inhibited PDE5 in APP/PS1 transgenic mice.

Although $\mathrm{AD}$ is a multifactor disease that the exact pathogenesis is not fully clarity, multiple lines of studies demonstrate that $A \beta$ aggregation in the brain is key factor for the development of AD (Sun et al., 2015; Sengupta et al., 2016). APP/PS1 transgenic model mouse is widely applied to many studies of AD that possesses the overexpression of human APP encoding gene and PS1 gene mutations, and which are related to the familial early-onset AD (Bilkei-Gorzo, 2014; Allue et al., 2016; Choi et al., 2016). In addition, the mouse is not only capable of modeling some main pathological characteristics of $\mathrm{AD}$ via the excessive accumulation of $\mathrm{A} \beta$, but also the appearance of senile plaque and cognitive dysfunction (Chin, 2011; Chouraki and Seshadri, 2014). Therefore, this study used 12-month-old male APP/PS1 mice to detect the effects of ICS II on cognitive decline and $A \beta$ production. The MWM test results showed substantial spatial learning and memory disorder and neuron loss in APP/PS1 transgenic mice, which are consistent with previous studies (Zhang et al., 2011; Yang R.Y. et al., 2015). Importantly, the deficits were effectively restored by chronic treatment with ICS II. 

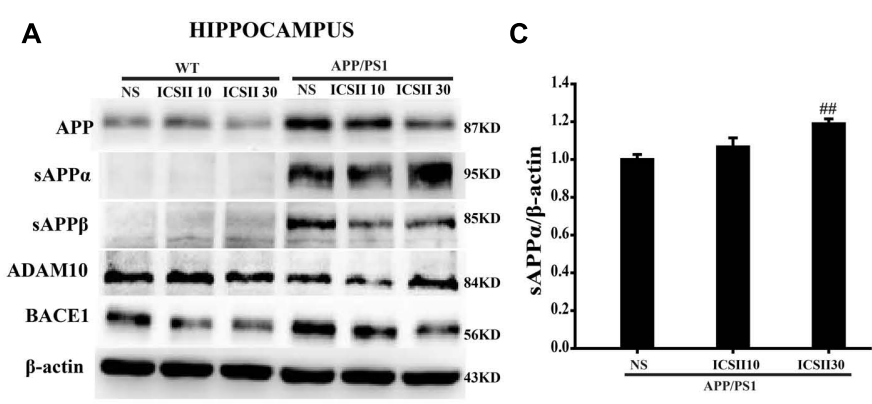

D

B

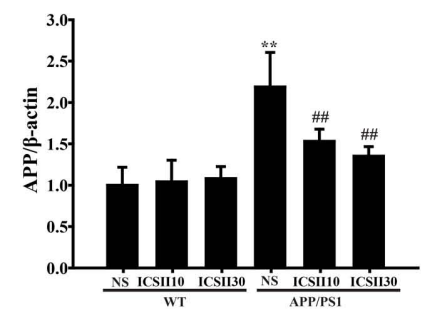

G
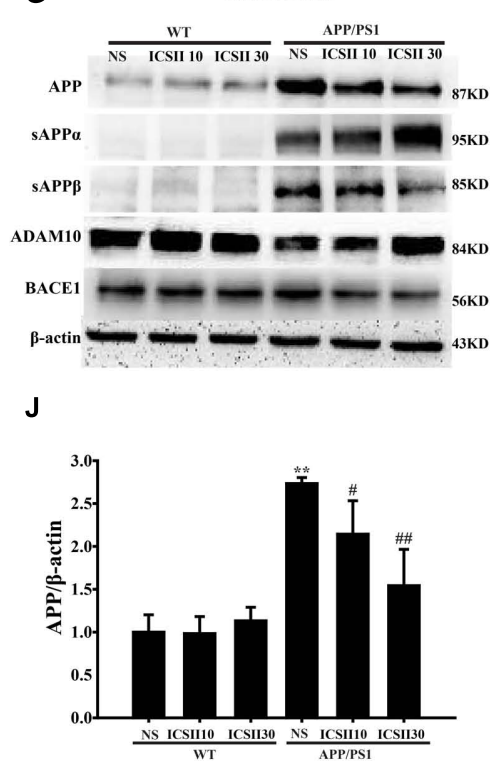

E

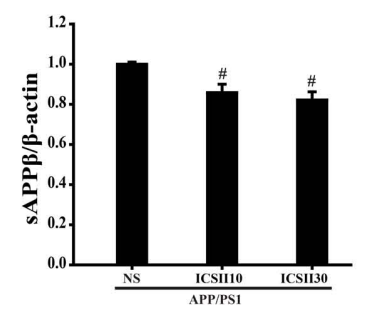

H

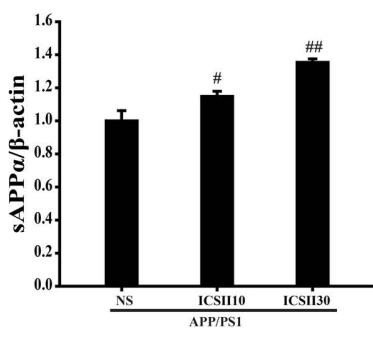

K

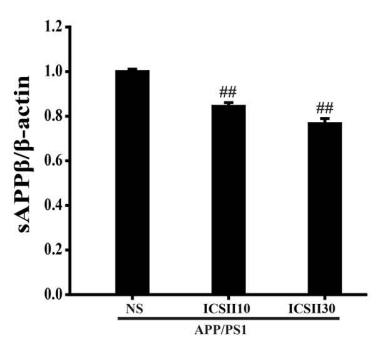

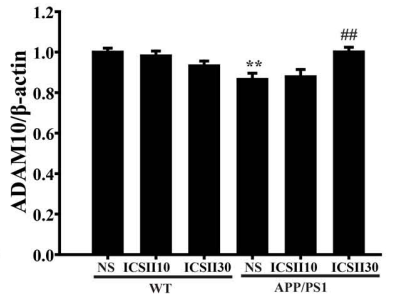

F

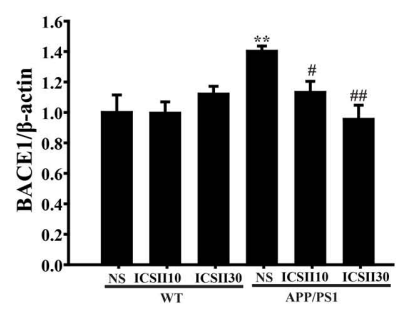

I

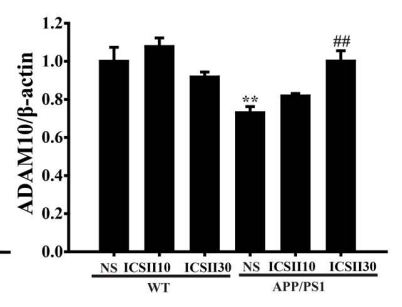

L

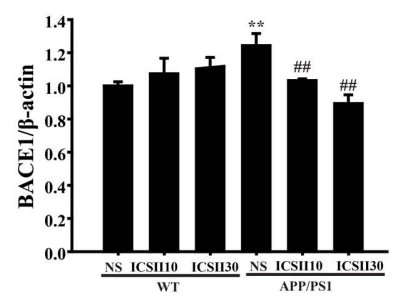

FIGURE 4 | Effect of ICS II on process of amyloid- $\beta$ production in the hippocampus and cortex of APP/PS1 transgenic mice. (A,G) The antibody-reactive bands of APP, sAPP $\alpha$, and ADAM10 as well as SAPP $\beta$ and BACE1 in the hippocampus and cortex of different groups. (B,J) Quantitative analysis of APP protein expression. (C,H) Quantitative analysis of sAPP $\alpha$ protein expression. (E,K) Quantitative analysis of sAPP $\beta$ protein expression. (D,I) Quantitative analysis of ADAM10 protein expression. (F,L) Quantitative analysis of BACE1 protein expression. The relative optical density was normalized to $\beta$-actin. Data are presented as mean \pm SEM $\left(n=3\right.$ each), ${ }^{* *} p<0.01$ vs. WT+NS, ${ }^{\#} p<0.05,{ }^{\# \#} p<0.01$ vs. APP/PS1+NS. SEM, standard error of the mean; NS, normal saline; APP, amyloid precursor protein; SAPP $\alpha$, soluble APP- $\alpha$; sAPP $\beta$, soluble APP- $\beta$; BACE1, $\beta$-site APP cleavage enzyme 1; ADAM10, a disintegrin and metalloproteinase domain 10.

PDE5 is a $3^{\prime}, 5^{\prime}$ cyclic guanosine monophosphate hydrolase (Garcia-Osta et al., 2012). Clinically, PDE5-Is are used for treating secondary pulmonary hypertension (Das et al., 2015), and there are recent emerging interests in its role on neurodegenerative diseases (Garcia-Osta et al., 2012). A series of previous evidence indicates that PDE5-Is could improve memory performance in animal models of $\mathrm{AD}$ via suppressing the levels of $A \beta$ contents (Zhang et al., 2013b) and inhibiting the effect of induced neuronal loss (Yin et al., 2016). It also shows beneficial effects on amyloid deposition (Puzzo et al., 2009). Recently, we found that ICS II as a PDE5-I protects against $\mathrm{H}_{2} \mathrm{O}_{2}$-induced PC12 cells death and attenuates STZ-induced cognitive deficits in rats (Yin et al., 2016; Gao et al., 2017). In this present study, the increased protein expression of PDE5 was found in the 
A

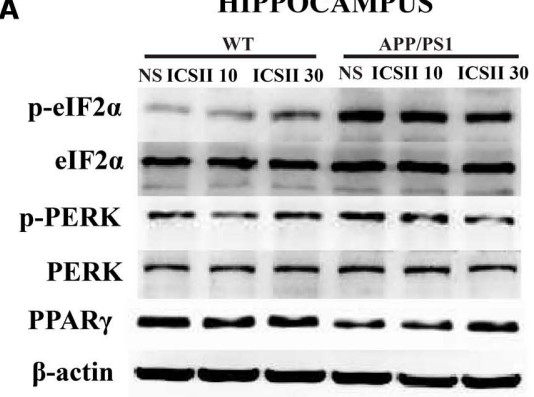

C

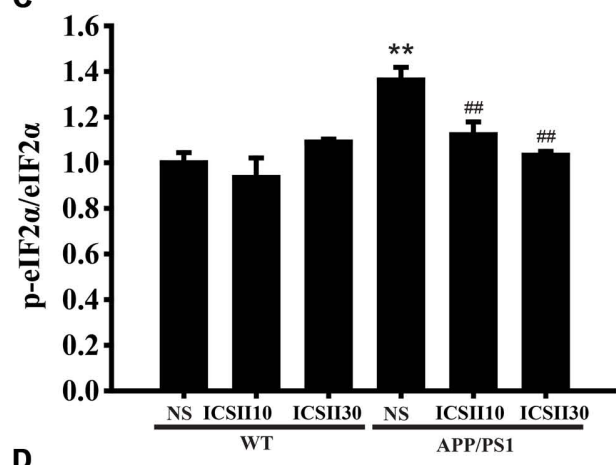

D

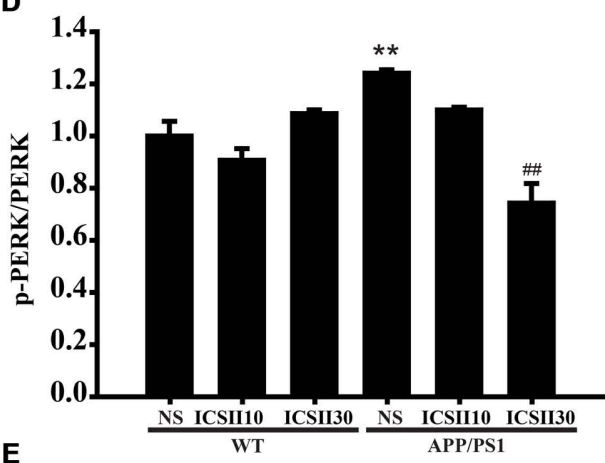

B
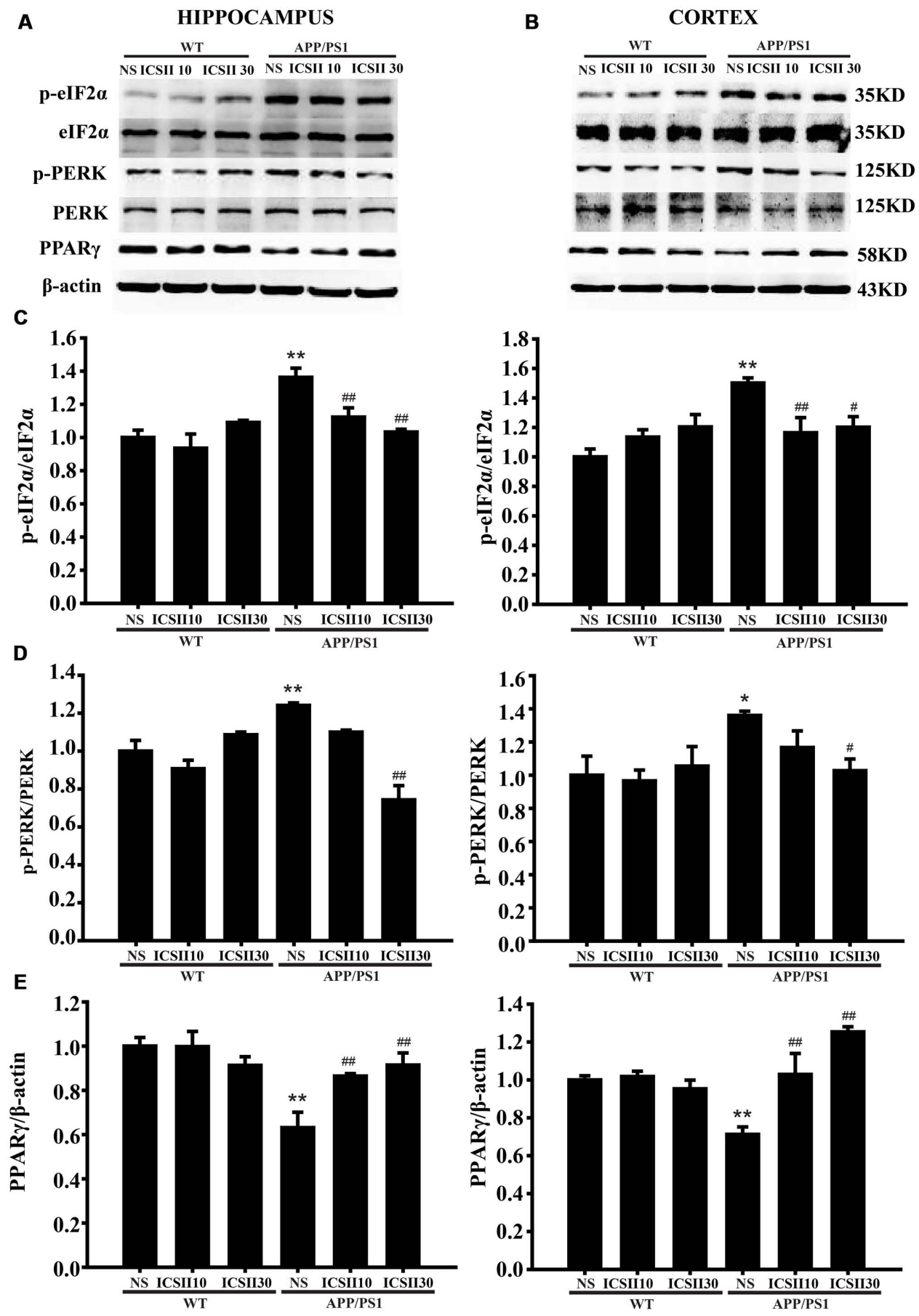

FIGURE 5 | Effects of ICS II on the PPAR $\gamma$ expression and the phosphorylation levels of elF2 $\alpha$ and PERK in APP/PS1 transgenic mice. (A,B) The antibody-reactive bands of p-elF2 $\alpha, \mathrm{p}$-PERK, and PPAR $\gamma$ in the hippocampus and cortex of different groups. (C) Quantitative analysis of $\mathrm{p}$-elF2 $\alpha$ levels.

(D) Quantitative analysis of p-PERK levels. The relative optical density was normalized to elF2 $\alpha$ and PERK. (E) Quantitative analysis of PPAR $\gamma$ protein expression. The relative optical density was normalized to $\beta$-actin. Data are presented as mean \pm SEM $\left(n=3\right.$ each), ${ }^{*} p<0.05,{ }^{* *} p<0.01$ vs. WT+NS, ${ }^{\#} p<0.05$, ${ }^{\# \#} p<0.01$ vs. APP/PS1+NS. SEM, standard error of the mean; NS, normal saline; elF2 $\alpha$, eukaryotic initiation factor $\alpha$; PERK, PKR endoplasmic reticulum regulating kinase; PPAR $\gamma$, peroxisome proliferator-activated receptor- $\gamma$.

brains of APP/PS1 transgenic mice, which is consistent with prior observations (Zhang et al., 2013a; Jin et al., 2014). Thus, we speculated that PDE5 might be involved in the pathogenesis of
AD. As expected, ICS II reversed the aberrantly elevated PDE5A protein expression and competed with the cleaved process of APP and further prevented the A $\beta$ production, which finally 
A
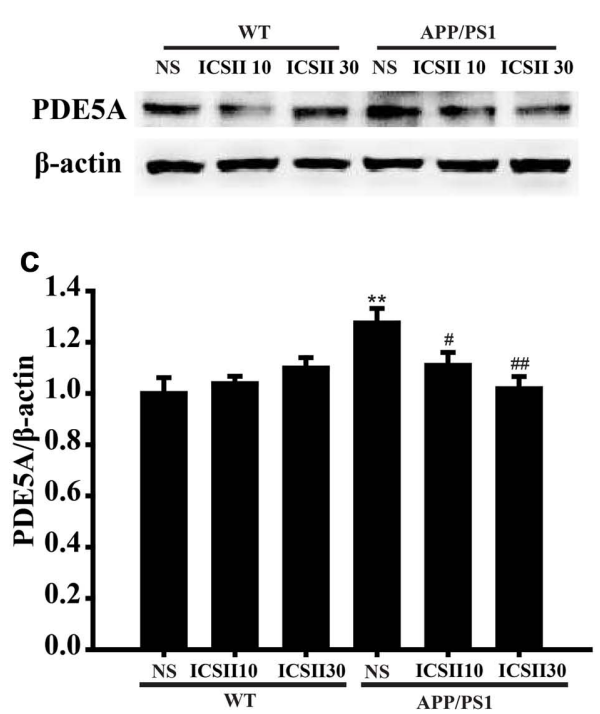

B

B CORTEX
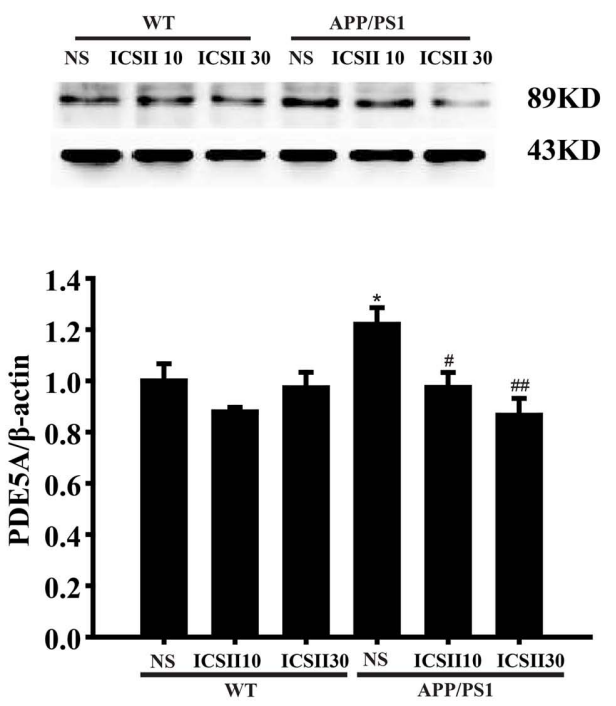

FIGURE 6 | Effects of ICS II on the protein expression of PDE5A in the hippocampus and cortex of APP/PS1 transgenic mice. (A,B) The antibody-reactive bands of PDE5A in the hippocampus and cortex of different groups. (C) Quantitative analysis of PDE5A protein expression. The relative optical density was normalized to $\beta$-actin. Data are presented as mean \pm SEM $\left(n=3\right.$ each) ${ }^{*} p<0.05,{ }^{* *} p<0.01$ vs. WT+NS, ${ }^{\#} p<0.05$, ${ }^{\#} p<0.01$ vs. APP/PS1+NS SEM, standard error of the mean; NS, normal saline; PDE5A, phosphodiesterase type 5A.

led to the improvement of the cognitive functions in APP/PS1 transgenic mice. Those results demonstrated that ICS II might work as a PDE5 inhibitor for improving $\mathrm{AD}$ symptoms in this mouse model. Lamentedly, it is not clear how ICS II regulates the catalytic activity of PDE5, this effect is necessary to delineate in future experiment.

Extracellular deposition of senile plaque is widely recognized to a critical pathological feature of AD (Joshi et al., 2015) and represents the most significant neuropathological histological feature of the $\mathrm{AD}$ (Nilsson et al., 2013). In the $\mathrm{AD}$ patients, senile plaques were detected in the hippocampus (Sabri et al., 2015; Witte et al., 2015). Accumulating evidences have shown that 9-month-old APP/PS1 transgenic mice exhibited the formation of senile plaques which gradually increased with age (Bibari et al., 2013; He et al., 2014). Thioflavine S staining results showed that ICS II could efficiently ameliorate the histopathological lesions.

Beta-amyloid peptides are involved in the formation of senile plaques (Sengupta et al., 2016). The most common A $\beta$ peptides consist of 39-43 amino acids. There are two major isoforms of $A \beta$, soluble $A \beta_{40}$, and insoluble $A \beta_{42}$, but the latter peptide shows more prone to aggregation and stronger neurotoxicity. A series of studies have elucidated elevated levels of $A \beta_{1-40}$ and $\mathrm{A} \beta_{1-42}$ in the model mice of $\mathrm{AD}$, which may be the critical factor for causing neuronal deficits and inhibiting the longterm potentiation (LTP) (Zhu et al., 2013; He et al., 2014; Jin et al., 2014). Furthermore, the levels of $\mathrm{A} \beta$ contents correlate negatively with the spatial learning and memory functions. Interestingly, the levels of both $\mathrm{A} \beta$ contents were potently inhibited in ICS II-treated APP/PS1 mice and the underlying mechanisms are involved in regulating the process of APP, including non-amyloidogenic and amyloidogenic pathways to preclude the generation of A $\beta$. APP is a precursor of $A \beta$-peptides (Iakoucheva et al., 2016) and is cleaved by two enzymes ( $\beta$ - and $\gamma$-secretases) (Salminen et al., 2013), which are essential steps for generating pathogenic $A \beta$ peptides (a central component of senile plaques in AD brains). It should be noted that the majority of APP is cleaved by $\alpha$-secretase causing the secretion of $\operatorname{sAPP} \alpha$, an APP extracellular fragment, and the formation of a membrane-bound 83 amino acid fragment (C83). sAPP $\alpha$ exhibits neuroprotective, neurotrophic, and neurogenic properties (Nalivaeva et al., 2014). Moreover, promoting APP $\alpha$-secretase cleavage is considered as an approach to decrease the $\mathrm{A} \beta$ production, in particular because a-secretase appears to compete with BACE1 cleavage site (Saftig and Lichtenthaler, 2015). The balance of $\alpha / \beta$-secretases were broken, which leads to non-amyloidogenic cleavage process is gradually interrupted and further facilitates $A \beta$ production in APP/PS1 transgenic mice (He et al., 2014). Several members of the ADAM family, such as ADAM10 and ADAM9 as well as ADAM17, are involved in the activity of $\alpha$-secretase. Functionally, ADAM10 has neuroprotective and neurotrophic effects, it was defined as the most important member of ADAMs family of $\alpha$-secretase, which is essential for neurogenesis and development of the embryonic brain (Vassar, 2013; Du et al., 2016). Therefore, promoting ADAM10 protein expression is widely considered to be an effective approach for AD treatment, and the reduced protein expression of ADAM10 has been linked to the molecular pathogenesis of AD (Saftig and Lichtenthaler, 2015). Our results found that inhibition of ADAM10 led to abnormal elevation of $\mathrm{A} \beta$ contents in vivo. Notably, treatment with ICS II greatly increased ADAM10 expression in the hippocampus and cortex in a concentration dose-dependent manner. 


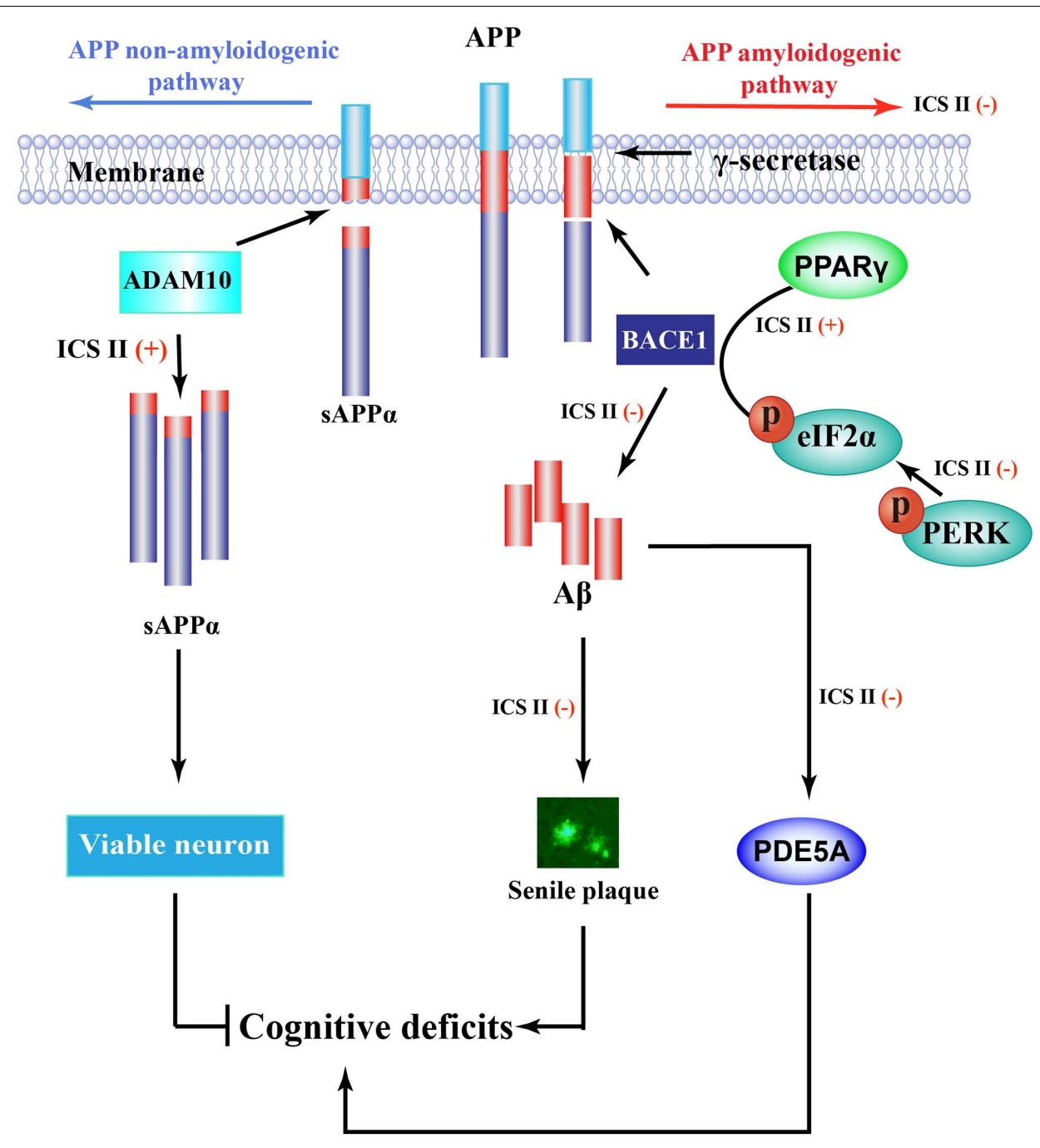

FIGURE 7 | Overview diagram illustrates the mechanism of ICS II-mediated A $\beta$ production. A $\beta$ is generated from a sequent cleavage of APP by BACE1 and $\gamma$-secretase, ICS II suppressed PPAR $\gamma$ degeneration as well as inhibition of PERK/elF2 $\alpha$ phosphorylation, causing the inhibition of BACE1 and further the inhibition of $A \beta$ production and senile plaque formation. In addition, ICS II prompted non-amyloidogenic cleavage process via increasing ADAM10 protein expression,

Furthermore, ICS II protected against cognitive deficits may be closely interrelated to inhibition of PDE5.

Previous studies have documented that abnormal protein expression of APP and BACE1 could facilitate $\mathrm{A} \beta$ production in $\mathrm{AD}$ mice and our experiment results agreed with this (Jin et al., 2014; Li et al., 2015; Du et al., 2016). BACE1 is a type I transmembrane aspartic protease that is responsible for cleaving APP at the $\beta$-secretase cleavage site to generate sAPP $\beta$ and formation of a 99-amino-acid-long C-terminal membranebound fragment (C99). In addition, BACE1 undergoes several posttranslational modifications, including phosphorylation, $N$-glycosylation and ubiquitination (Sjölander et al., 2010; Motoki et al., 2012; Vassar et al., 2014). Because of BACE1 prime physiological functions, it has received intensely attention as a promising novel strategy against $\mathrm{AD}$. It was proved that the transcription factor with putative binding sites to be involved in BACE1 expression in AD. eIF2 $\alpha$ is an important signaling pathway that affects cognitive functions.
The phosphorylation level of eIF2 $\alpha$ positively correlated with BACE1 expression level, which can increased the protein level of BACE1 in $5 \times$ FAD mice (Devi and Ohno, 2012, 2013). Similarly, phosphorylated eIF $2 \alpha$ at Ser 51 are aberrantly elevated associated with the degeneration of neurons in $\mathrm{AD}$ patients (Vassar, 2008; Bose et al., 2011). Moreover, PERK as an eIF2 $\alpha$ kinase acts on eIF2 $\alpha$ phosphorylation site and its phosphatase activity has also been closely related to the increase of BACE1 level (Devi and Ohno, 2014; Yang et al., 2016). In our study, we also found that BACE1, the levels of phosphorylated eIF2 $\alpha$ and PERK were significantly higher in APP/PS1 transgenic mice. A progressive enhancement of eIF2 $\alpha /$ PERK phosphorylation is responsible for BACE1 overexpression and eventually up-regulation of $A \beta$ production in vivo and in vitro (Zhu et al., 2013; Zhang et al., 2016). If this were the case, then the fact that chronic treatment 
of ICS II reversed the induction of PERK-eIF2 $\alpha$ pathway may further support the potential utility of ICS II in the treatment of AD. PPAR $\gamma$ is a transcription factor that modulates $A \beta$ metabolism via inhibiting BACE1 transcription (Katsouri et al., 2011). Meanwhile, PPAR $\gamma$ signaling pathway is involved in ameliorating $\mathrm{AD}$ pathology along with its anti-inflammatory activity. Conversely, activation of the inflammatory factors could reverse activated BACE1 expression and further facilitated $\mathrm{A} \beta$ secretion (Katsouri et al., 2011; Strobel et al., 2015). In addition, PPAR $\gamma$ enhancement resulted in suppression of APP expression through promoting ubiquitination of APP and subsequent degradation in SHSY5YAPP+ cells (Scuderi et al., 2014). In the present study, we evaluated the expression of PPAR $\gamma$ in vivo. Similar to previous findings, we found that PPAR $\gamma$ inhibition could contribute to the elevation of BACE1, which further aggravated APP-A $\beta$ process, and eventually resulted in neurons degradation. Remarkably, ICS II could reduce A $\beta$ production by inducing PPAR $\gamma$ activation, ultimately ameliorating the impairment of learning and memory functions.

In summary (Figure 7), this study demonstrated that ICS II as a broad spectrum anti-cancer natural compound that remarkably ameliorates learning and memory functions impairment interferes with multiple pathogenic mechanisms, including decreasing the formation of senile plaque, $A \beta$ generation and the neuronal degradation in APP/PS1 transgenic mice. The protective mechanisms are likely attributable to increased ADAM10 activation and suppression of APP and BACE1 expression, these effects appear to be due to the inhibition

\section{REFERENCES}

Allue, J. A., Sarasa, L., Izco, M., Perez-Grijalba, V., Fandos, N., PascualLucas, M., et al. (2016). Outstanding phenotypic differences in the profile of amyloid-beta between Tg2576 and APPswe/PS1dE9 transgenic mouse models of Alzheimer's Disease. J. Alzheimers Dis. 53, 773-785. doi: 10.3233/JAD160280

Alzheimer's Association (2015). 2015 Alzheimer's disease facts and figures. Alzheimers Dement. 11, 332-384.

Anand, R., Gill, K. D., and Mahdi, A. A. (2013). Therapeutics of Alzheimer's disease: past, present and future. Neuropharmacology 76, 27-50. doi: 10.1016/ j.neuropharm.2013.07.004

Bibari, O., Lee, S., Dickson, T. C., Mitew, S., Vickers, J. C., and Chuah, M. I. (2013). Denervation of the olfactory bulb leads to decreased Abeta plaque load in a transgenic mouse model of Alzheimer's disease. Curr. Alzheimer Res. 10, 688-696.

Bilkei-Gorzo, A. (2014). Genetic mouse models of brain ageing and Alzheimer's disease. Pharmacol. Ther. 142, 244-257. doi: 10.1016/j.pharmthera.2013.12.009

Bose, A., Mouton-Liger, F., Paquet, C., Mazot, P., Vigny, M., Gray, F., et al. (2011). Modulation of tau phosphorylation by the kinase PKR: implications in Alzheimer's Disease. Brain Pathol. 21, 189-200. doi: 10.1111/j.1750-3639.2010. 00437.x

Cao, G., Su, P., Zhang, S., Guo, L., Zhang, H., Liang, Y., et al. (2016). Ginsenoside Re reduces $A \beta$ production by activating PPAR $\gamma$ to inhibit BACE1 in N2a/APP695 cells. Eur. J. Pharmacol. 793, 101-108. doi: 10.1016/j.ejphar.2016.11.006

Carrillo, M. C., Dean, R. A., Nicolas, F., Miller, D. S., Berman, R., Khachaturian, Z., et al. (2013). Revisiting the framework of the National Institute on AgingAlzheimer's Association diagnostic criteria. Alzheimers Dement. 9, 594-601. doi: 10.1016/j.jalz.2013.05.1762

Chin, J. (2011). Selecting a mouse model of Alzheimer's disease. Methods Mol. Biol. 670, 169-189. doi: 10.1007/978-1-60761-744-0_13 of PERK/eIF2 $\alpha /$ PPAR $\gamma$ signaling pathway. In addition, ICS II protected against cognitive deficits may be closely interrelated to inhibition of PDE5A protein. Combined, the findings provide strong evidence that ICS II may be developed as a potently promising natural compound candidate for halting progression of AD. Nonetheless, the selective PDE5A agonists, BrdU immunohistochemistry and confocal microscopy is under used to further clarify the exact mechanism of ICS II on AD, and that will be as the next chapter in this story.

\section{AUTHOR CONTRIBUTIONS}

QG and JS: Designed the research; LY and YL: performed the research; FL and JG: analyzed the data; LY: wrote the paper. QG and YD: modified the paper. All authors agreed on the final version of the manuscript.

\section{ACKNOWLEDGMENTS}

This work was supported by the National Natural Science Foundation of China (Grant No. 81560585), Program for excellent young talents of Zunyi Medical University (Grant No. 15zy-002), and Science and Technology Innovation Talent Team of Guizhou Province (Grant No. 20154023) and Outstanding Youth Science and Technology Talent Capital of Guizhou Province (Grant No. 201326).

Choi, Y., Jeong, H. J., Liu, Q. F., Oh, S. T., Koo, B. S., Kim, Y., et al. (2016). Clozapine improves memory impairment and reduces abeta level in the $\mathrm{Tg}$ APPswe/PS1dE9 mouse model of Alzheimer's Disease. Mol. Neurobiol. 54, 450-460. doi: 10.1007/s12035-015-9636-x

Chouraki, V., and Seshadri, S. (2014). Genetics of Alzheimer's disease. Adv. Genet. 87, 245-294. doi: 10.1016/B978-0-12-800149-3.00005-6

Das, A., Durrant, D., Salloum, F. N., Xi, L., and Kukreja, R. C. (2015). PDE5 inhibitors as therapeutics for heart disease, diabetes and cancer. Pharmacol. Ther. 147, 12-21. doi: 10.1016/j.pharmthera.2014.10.003

Deng, Y., Xiong, D., Yin, C., Liu, B., Shi, J., and Gong, Q. (2016). Icariside II protects against cerebral ischemia-reperfusion injury in rats via nuclear factor-kappaB inhibition and peroxisome proliferator-activated receptor upregulation. Neurochem. Int. 96, 56-61. doi: 10.1016/j.neuint.2016.02.015

Devi, L., and Ohno, M. (2012). Phospho-eIF2 $\alpha$ level is important for determining abilities of BACE1 reduction to rescue cholinergic neurodegeneration and memory defects in 5XFAD Mice. PLoS ONE 5:e12974. doi: 10.1371/journal. pone. 0012974

Devi, L., and Ohno, M. (2013). Deletion of the eIF2 $\alpha$ Kinase GCN2 fails to rescue the memory decline associated with Alzheimer's disease. PLoS ONE 8:e77335. doi: 10.1371/journal.pone.0077335

Devi, L., and Ohno, M. (2014). PERK mediates eIF2 $\alpha$ phosphorylation responsible for BACE1 elevation, CREB dysfunction and neurodegeneration in a mouse model of Alzheimer's disease. Neurobiol. Aging 35, 2272-2281. doi: 10.1016/j. neurobiolaging.2014.04.031

Du, Y., Qu, J., Zhang, W., Bai, M., Zhou, Q., Zhang, Z., et al. (2016). Morin reverses neuropathological and cognitive impairments in APPswe/PS1dE9 mice by targeting multiple pathogenic mechanisms. Neuropharmacology 108, 1-13. doi: 10.1016/j.neuropharm.2016.04.008

Fan, L. Y., and Chiu, M. J. (2014). Combotherapy and current concepts as well as future strategies for the treatment of Alzheimer's disease. Neuropsychiatr. Dis. Treat. 10, 439-451. doi: 10.2147/NDT.S45143 
Gao, J., Deng, Y., Yin, C., Liu, Y., Zhang, W., Shi, J., et al. (2017). Icariside II, a novel phosphodiesterase 5 inhibitor, protects against $\mathrm{H} 2 \mathrm{O} 2$-induced $\mathrm{PC} 12$ cells death by inhibiting mitochondria-mediated autophagy. J. Cell. Mol. Med. 21, 375-386. doi: $10.1111 /$ jcmm.12971

Garcia-Osta, A., Cuadrado-Tejedor, M., Garcia-Barroso, C., Oyarzabal, J., and Franco, R. (2012). Phosphodiesterases as therapeutic targets for Alzheimer's disease. ACS Chem. Neurosci. 3, 832-844. doi: 10.1021/cn3000907

He, X. L., Yan, N., Zhang, H., Qi, Y. W., Zhu, L. J., Liu, M. J., et al. (2014). Hydrogen sulfide improves spatial memory impairment and decreases production of Abeta in APP/PS1 transgenic mice. Neurochem. Int. 67, 1-8. doi: 10.1016/j. neuint.2014.01.004

Iakoucheva, L. M., Laßek, M., Weingarten, J., Wegner, M., Mueller, B. F., Rohmer, M., et al. (2016). APP is a context-sensitive regulator of the hippocampal presynaptic active zone. PLOS Comput. Biol. 12:e1004832. doi: 10.1371/journal.pcbi.1004832

Jin, F., Gong, Q. H., Xu, Y. S., Wang, L. N., Jin, H., Li, F., et al. (2014), Icariin, a phosphodiesterase-5 inhibitor, improves learning and memory in APP/PS1 transgenic mice by stimulation of NO/cGMP signalling. Int. J. Neuropsychopharmacol. 17, 871-881. doi: 10.1017/S1461145713001533

Joshi, G., Gan, K. A., Johnson, D. A., and Johnson, J. A. (2015). Increased Alzheimer's disease-like pathology in the APP/PS1DeltaE9 mouse model lacking Nrf2 through modulation of autophagy. Neurobiol. Aging 36, 664-679. doi: 10.1016/j.neurobiolaging.2014.09.004

Katsouri, L., Parr, C., Bogdanovic, N., Willem, M., and Sastre, M. (2011). PPARgamma co-activator-1alpha (PGC-1alpha) reduces amyloid-beta generation through a PPARgamma-dependent mechanism. J. Alzheimers Dis. 25, 151-162. doi: 10.3233/JAD-2011-101356

Li, F., Dong, H. X., Gong, Q. H., Wu, Q., Jin, F., and Shi, J. S. (2015). Icariin decreases both APP and Abeta levels and increases neurogenesis in the brain of Tg2576 mice. Neuroscience 304, 29-35. doi: 10.1016/j.neuroscience.2015.06.010

Liu, H., Deng, Y., Gao, J., Liu, Y., Li, W., Shi, J., et al. (2015). Sodium hydrosulfide attenuates beta-amyloid-induced cognitive deficits and neuroinflammation via modulation of MAPK/NF- $\mathrm{B}$ pathway in rats. Curr. Alzheimer Res. 12, 673-683.

Motoki, K., Kume, H., Oda, A., Tamaoka, A., Hosaka, A., Kametani, F., et al. (2012). Neuronal beta-amyloid generation is independent of lipid raft association of beta-secretase BACE1: analysis with a palmitoylation-deficient mutant. Brain Behav. 2, 270-282. doi: 10.1002/brb3.52

Nalivaeva, N. N., Belyaev, N. D., Kerridge, C., and Turner, A. J. (2014). Amyloidclearing proteins and their epigenetic regulation as a therapeutic target in Alzheimer's disease. Front. Aging Neurosci. 6:235. doi: 10.3389/fnagi.2014.00235

Nilsson, P., Loganathan, K., Sekiguchi, M., Matsuba, Y., Hui, K., Tsubuki, S., et al. (2013). A $\beta$ secretion and plaque formation depend on autophagy. Cell Rep. 5, 61-69. doi: 10.1016/j.celrep.2013.08.042

Puzzo, D., Staniszewski, A., Deng, S. X., Privitera, L., Leznik, E., Liu, S., et al. (2009). Phosphodiesterase 5 inhibition improves synaptic function, memory, and amyloid-beta load in an Alzheimer's disease mouse model. J. Neurosci. 29, 8075-8086. doi: 10.1523/JNEUROSCI.0864-09.2009

Sabri, O., Sabbagh, M. N., Seibyl, J., Barthel, H., Akatsu, H., Ouchi, Y., et al. (2015). Florbetaben PET imaging to detect amyloid beta plaques in Alzheimer's disease: phase 3 study. Alzheimers Dement. 11, 964-974. doi: 10.1016/j.jalz.2015.02.004

Saftig, P., and Lichtenthaler, S. F. (2015). The alpha secretase ADAM10: A metalloprotease with multiple functions in the brain. Prog. Neurobiol. 135, 1-20. doi: 10.1016/j.pneurobio.2015.10.003

Salminen, A., Kaarniranta, K., Kauppinen, A., Ojala, J., Haapasalo, A., Soininen, H., et al. (2013). Impaired autophagy and APP processing in Alzheimer's disease: the potential role of Beclin 1 interactome. Prog. Neurobiol. 10, 33-54. doi: 10.1016/j.pneurobio.2013.06.002

Sankaranarayanan, S., Price, E. A., Wu, G., Crouthamel, M. C., Shi, X. P., Tugusheva, K., et al. (2008). In vivo beta-secretase 1 inhibition leads to brain Abeta lowering and increased alpha-secretase processing of amyloid precursor protein without effect on neuregulin-1. J. Pharmacol. Exp. Ther. 324, 957-969. doi: $10.1124 /$ jpet.107.130039

Scuderi, C., Steardo, L., and Esposito, G. (2014). Cannabidiol promotes amyloid precursor protein ubiquitination and reduction of beta amyloid expression in SHSY5YAPP + cells through PPARgamma involvement. Phytother. Res. 28, 1007-1013. doi: 10.1002/ptr.5095
Sengupta, U., Nilson, A. N., and Kayed, R. (2016). The role of amyloid-beta oligomers in toxicity, propagation, and immunotherapy. EBioMedicine 6, 42-49. doi: 10.1016/j.ebiom.2016.03.035

Sjölander, A., Zetterberg, H., Andreasson, U., Minthon, L., and Blennow, K. (2010). BACE1 gene variants do not influence BACE1 activity, levels of APP or A $\beta$ isoforms in CSF in Alzheimer's disease. Mol. Neurodegener. 5, 37. doi: 10.1186/ 1750-1326-5-37

Strobel, S., Grunblatt, E., Riederer, P., Heinsen, H., Arzberger, T., Al-Sarraj, S., et al. (2015). Changes in the expression of genes related to neuroinflammation over the course of sporadic Alzheimer's disease progression: CX3CL1, TREM2, and PPARgamma. J. Neural. Transm. (Vienna) 122, 1069-1076. doi: 10.1007/ s00702-015-1369-5

Sun, X., Chen, W. D., and Wang, Y. D. (2015). beta-Amyloid: the key peptide in the pathogenesis of Alzheimer's disease. Front. Pharmacol. 6:221. doi: 10.3389/ fphar.2015.00221

Sze, S. C., Tong, Y., Ng, T. B., Cheng, C. L., and Cheung, H. P. (2010). Herba epimedii: anti-oxidative properties and its medical implications. Molecules 15, 7861-7870. doi: 10.3390/molecules15117861

Vassar, R. (2008). Phosphorylation of the translation initiation factor eIF2alpha increases BACE1 levels and promotes amyloidogenesis. Educ. Comp. 60, 9881009. doi: 10.1016/j.neuron.2008.10.047

Vassar, R. (2013). ADAM10 prodomain mutations cause late-onset Alzheimer's disease: not just the latest FAD. Neuron 80, 250-253. doi: 10.1016/j.neuron. 2013.09.031

Vassar, R., Kuhn, P. H., Haass, C., Kennedy, M. E., Rajendran, L., Wong, P. C., et al. (2014). Function, therapeutic potential and cell biology of BACE proteases: current status and future prospects. J. Neurochem. 130, 4-28. doi: 10.1111/jnc. 12715

Witte, M. M., Foster, N. L., Fleisher, A. S., Williams, M. M., Quaid, K., Wasserman, M., et al. (2015). Clinical use of amyloid-positron emission tomography neuroimaging: practical and bioethical considerations. Alzheimers Dement. (Amst) 1, 358-367. doi: 10.1016/j.dadm.2015.06.006

Xie, Q., Wen, H., Zhang, Q., Zhou, W., Lin, X., Xie, D., et al. (2016). Inhibiting PI3K-AKt signaling pathway is involved in antitumor effects of ginsenoside Rg3 in lung cancer cell. Biomed. Pharmacother. 85, 16-21. doi: 10.1016/j.biopha. 2016.11.096

Yan, B. Y., Pan, C. S., Mao, X. W., Yang, L., Liu, Y. Y., Yan, L., et al. (2014). Icariside II improves cerebral microcirculatory disturbance and alleviates hippocampal injury in gerbils after ischemia-reperfusion. Brain Res. 1573, 63-73. doi: 10. 1016/j.brainres.2014.05.023

Yang, R. Y., Zhao, G., Wang, D. M., Pang, X. C., Wang, S. B., Fang, J. S., et al. (2015). DL0410 can reverse cognitive impairment, synaptic loss and reduce plaque load in APP/PS1 transgenic mice. Pharmacol. Biochem. Behav. 139, 15-26. doi: 10.1016/j.pbb.2015.10.009

Yang, X.-D., Yang, Y.-Y., Ouyang, D.-S., and Yang, G.-P. (2015). A review of biotransformation and pharmacology of ginsenoside compound K. Fitoterapia 100, 208-220. doi: 10.1016/j.fitote.2014.11.019

Yang, W., Zhou, X., Zimmermann, H. R., Cavener, D. R., Klann, E., and Ma, T. (2016). Repression of the eIF2alpha kinase PERK alleviates mGluR-LTD impairments in a mouse model of Alzheimer's disease. Neurobiol. Aging 41, 19-24. doi: 10.1016/j.neurobiolaging.2016.02.005

Yin, C., Deng, Y., Gao, J., Li, X., Liu, Y., and Gong, Q. (2016). Icariside II, a novel phosphodiesterase-5 inhibitor, attenuates streptozotocin-induced cognitive deficits in rats. Neuroscience 328, 69-79. doi: 10.1016/j.neuroscience. 2016.04.022

Zhang, J., Guo, J., Xin, Z., Chen, Z., Gang, W., Liu, A., et al. (2013a). Phosphodiesterase-5 inhibitor sildenafil prevents neuroinflammation, lowers beta-amyloid levels and improves cognitive performance in APP/PS1 transgenic mice. Behav. Brain Res. 250, 230-237. doi: 10.1016/j.bbr.2013.05.017

Zhang, J., Guo, J., Zhao, X., Chen, Z., Wang, G., Liu, A., et al. (2013b). Phosphodiesterase-5 inhibitor sildenafil prevents neuroinflammation, lowers beta-amyloid levels and improves cognitive performance in APP/PS1 transgenic mice. Behav. Brain Res. 250, 230-237. doi: 10.1016/j.bbr.2013.05.017

Zhang, J. S., Zhou, S. F., Wang, Q., Guo, J. N., Liang, H. M., Deng, J. B., et al. (2016). Gastrodin suppresses BACE1 expression under oxidative stress condition via inhibition of the PKR/eIF2alpha pathway in Alzheimer's disease. Neuroscience 325, 1-9. doi: 10.1016/j.neuroscience.2016.03.024 
Zhang, W., Hao, J., Liu, R., Zhang, Z., Lei, G., Su, C., et al. (2011). Soluble Abeta levels correlate with cognitive deficits in the 12-month-old APPswe/PS1dE9 mouse model of Alzheimer's disease. Behav. Brain Res. 222, 342-350. doi: 10.1016/j.bbr.2011.03.072

Zhang, X., and Song, W. (2013). The role of APP and BACE1 trafficking in APP processing and amyloid- $\beta$ generation. Alzheimers Res. Ther. 5, 46-46.

Zhu, Z., Yan, J., Jiang, W., Yao, X. G., Chen, J., Chen, L., et al. (2013). Arctigenin effectively ameliorates memory impairment in Alzheimer's disease model mice targeting both beta-amyloid production and clearance. J. Neurosci. 33, 13138-13149. doi: 10.1523/JNEUROSCI.4790-12.2013
Conflict of Interest Statement: The authors declare that the research was conducted in the absence of any commercial or financial relationships that could be construed as a potential conflict of interest.

Copyright (c) 2017 Yan, Deng, Gao, Liu, Li, Shi and Gong. This is an open-access article distributed under the terms of the Creative Commons Attribution License (CC BY). The use, distribution or reproduction in other forums is permitted, provided the original author(s) or licensor are credited and that the original publication in this journal is cited, in accordance with accepted academic practice. No use, distribution or reproduction is permitted which does not comply with these terms. 